\title{
Carbon integral honeycomb monoliths as support of copper catalysts in the Kharasch-Sosnovsky oxidation of cyclohexene
}

\author{
J.M. Gatica ${ }^{\text {, }}$, A.L. García-Cabeza ${ }^{\text {b }}$, M.P. Yeste ${ }^{\mathrm{a}}$, R. Marín-Barrios ${ }^{\mathrm{b}}$, J.M. González-Leal ${ }^{\mathrm{c}}$, G. Blanco ${ }^{\text {a }}$, \\ G.A. Cifredo ${ }^{\text {a }}$, F.M. Guerra ${ }^{\mathrm{b}}$, H. Vidal ${ }^{\mathrm{a}, *}$
}

a Departamento C.M. I.M. y Química Inorgánica, Universidad de Cádiz, Puerto Real 11510, Spain

${ }^{\mathrm{b}}$ Departamento de Ouímica Orgánica, Universidad de Cádiz, Puerto Real 11510, Spain

${ }^{\mathrm{c}}$ Departamento de Física de la Materia Condensada, Universidad de Cádiz, Puerto Real 11510, Spain

\section{H I G H L I G H T S}

\section{- Cu catalysts supported on carbon} honeycomb monoliths in allylic oxidation reactions.

- High activity and stability in Kharasch-Sosnovsky allylic oxidation of cyclohexene.

- Drying way in catalyst preparation, conventional or by microwaves, affects activity.

- XPS shows the role of surface $\mathrm{Cu}^{2+}$ environment and deposition of reaction product.

- Promising alternative to homogeneous catalysis in the field of organic synthesis.

\section{A R T I C L E I N F O}

\section{Article history:}

Received 30 September 2015

Received in revised form 4 December 2015

Accepted 16 January 2016

Available online 22 January 2016

\section{Keywords:}

Copper catalysts

Carbon honeycomb monoliths

Allylic oxidation

Kharasch-Sosnovsky

Cyclohexene
G R A P H I C A L A B S T R A C T
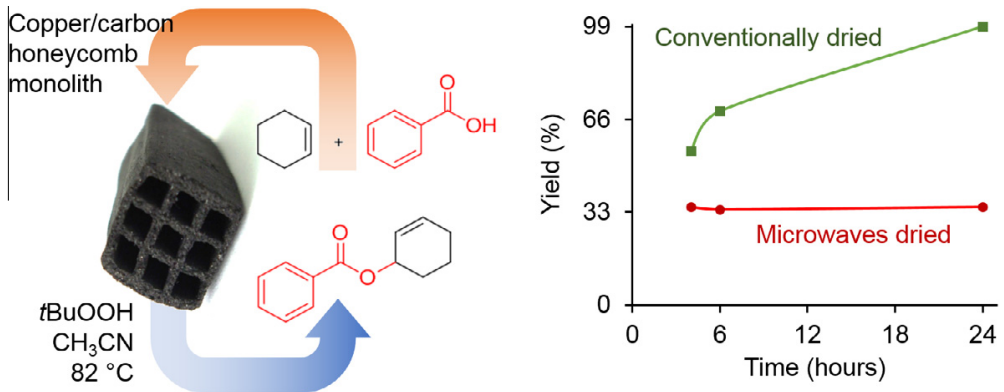

\section{A B S T R A C T}

Carbon integral honeycomb monoliths prepared from a natural coal were employed as support of copper catalysts for organic synthetic purposes. In particular good to excellent yields (60-100\% as function of the carboxylic acid employed) were obtained in the preparation of allylic esters by the Kharasch-Sosnovsky oxidation of cyclohexene. Different characterization techniques such as chemical analysis by Inductively Coupled Plasma Spectroscopy, nitrogen physisorption, X-ray Diffraction with Rietveld analysis, X-ray Photoelectron and Raman Spectroscopies, Temperature-Programmed Reduction and Scanning Electron Microscopy allowed finding that key parameters such as textural properties, degree of copper precursor decomposition and active phase homogeneity and dispersion can be modulated as function of a simple synthetic variable: the method used to dry the monoliths after impregnation with the metal precursor, either conventional or using microwaves. The results obtained allow understanding the key role of the nature and chemical surrounding $\left(\mathrm{O}^{2-}\right.$ anions or $\mathrm{OH}$ groups) of $\mathrm{Cu}^{2+}$ ions in the catalytic activity in the reaction investigated as well as the operating deactivation mechanisms. The use of the structured catalysts here proposed also opens up an interesting alternative to homogeneous catalysis in the field of organic synthesis.

(c) 2016 Elsevier B.V. All rights reserved.

\footnotetext{
* Corresponding author. Tel.: +34 956012744

E-mail address: hilario.vidal@uca.es (H. Vidal).
} 


\section{Introduction}

Carbon, especially upon activation, is one of the commonly employed materials for catalytic applications due to its interesting properties. This material is used either as adsorbent or catalytic support filters which are conventionally manufactured in the form of powders, granules, spheres, pellets or tablets [1]. Unlike ceramics, the honeycomb monolithic design is almost completely discarded for carbonaceous materials because they have been usually considered non-appropriate for extrusion.

Nevertheless, in previous studies we demonstrated that, with the use of appropriate additives, obtaining carbon integral honeycomb monoliths from coal is not only possible but also easily controllable following methodologies originally developed for ceramic materials that allow optimizing the composition of the carbonaceous dough in order to be extruded [2]. Further we showed that, among other applications such as the adsorption of volatile organic compounds in gas phase $[3,4]$ or the adsorption of organic pollutants in liquid phase [5], the resulting monoliths could be used as supports of $\mathrm{Cu}$ or Mn catalysts for low temperature selective catalytic reduction of NO [6], or even as active phase in the thermocatalytic decomposition of methane for $\mathrm{CO}_{2}$-free hydrogen production $[7,8]$. It is noteworthy that for all these applications related to environmental catalysis the advantage or need of the honeycomb monolithic design is highlighted [9].

In this work we extend the list of possible applications of carbon honeycomb monoliths as support by moving from an environmental use to the field of organic synthesis. In particular we investigate their potential to act as advantaged substrate of copper catalysts by screening their performance in the KharaschSosnovsky oxidation of olefins. This reaction has pulled the interest of synthetic chemists for a long time and copper compounds have been found to be efficient catalysts [10-13]. Most of the papers found in the literature deal with the attainment of enantiomeric versions of the reaction in the presence of chiral $\mathrm{N}$-based ligands. A drawback of many of these examples is the fact that the alkene partner is used in large excess, and the yield is given based on the oxidant. This is unacceptable when the olefin is very valuable. In the heterogeneous version, beyond some concrete examples, the literature is scarce and the main problem is frequently the selectivity [14-16]. The allylic oxidation of the olefin competes with the epoxidation of the double bond and the formation of overoxidation products is a recurrent problem.

According to previous studies, the reaction can be catalyzed by both $\mathrm{Cu}(\mathrm{I})$ and $\mathrm{Cu}(\mathrm{II})$ species. However, a recent investigation showed that for related reactions such as allylic hydroxylation of enones the $\mathrm{Cu}(\mathrm{II})$ species are preferred in comparison with $\mathrm{Cu}(0)$ or $\mathrm{Cu}(\mathrm{I})$ as far as they do not need further oxidation [17]. In this sense, we take advantage of our previous results that showed that depending on the preparative variables selected carbon honeycomb monoliths supported Cu catalysts may exhibit significant differences in the chemical state of the dispersed copper phase [6]. Moreover, the use of honeycomb monolithic catalysts allows making heterogeneous a process conventionally performed with copper salts in homogeneous phase [11,12], while adding the extra advantage of a structured material respect to those scarce works which employ powdered copper oxides $[18,19]$.

A physicochemical characterization of the catalysts prepared is performed, mainly before but also after their application to the reaction selected, in order to understand and hopefully optimize the observed catalytic behavior. For this purpose different techniques such as metal loading analysis by Inductively Coupled Plasma Atomic Emission Spectroscopy (ICP-AES), $\mathrm{N}_{2}$ physisorption, X-ray Diffraction (XRD), X-ray Photoelectron Spectroscopy (XPS), Raman Spectroscopy, Temperature-Programmed Reduction (TPR) and Scanning Electron Microscopy (SEM) with Energy Dispersive Spectroscopy (EDS) are employed. We particularly focus on the influence of the way of drying the monoliths after the impregnation with the copper precursor, either conventional or using microwaves, as this preparative variable showed in previous studies that can make a noteworthy difference [6].

The reaction is run in heterogeneous phase. First, an optimization of the experimental conditions of the Kharasch-Sosnovsky allylic oxidation of cyclohexene is performed by changing the carboxylic acid employed. For this stage of the study, pieces of the copper catalysts deposited onto the carbon honeycomb monoliths are used. Subsequently, entire monoliths are applied in those reaction conditions having shown high yields in the previous step. In this case special attention is paid to the catalytic stability of the monolithic samples with the time of use.

\section{Experimental section}

\subsection{Catalysts preparation}

The integral carbon honeycomb monoliths used in the present work were prepared from a medium volatile bituminous coal provided by the National Institute of Carbon (INCAR) in Spain, whose composition was $30 \mathrm{wt} \%$ of volatile and less than $6 \mathrm{wt} \%$ of ashes, and $75 \mathrm{vol} \%$ of vitrinite phase concerning its maceral composition. Its extrusion was achieved according to a previously reported methodology $[2,20]$, originally developed for ceramics by Casagrande and Atterberg [21]. In brief, this methodology allows predicting the extrudability of a paste by measuring simple parameters only related to its humidity, which avoid falling into a trial and error procedure. In general this is achieved by using additives that improve the handling characteristics and rheological properties of the paste during the kneading and extrusion operations, and give greater mechanical strength to the final heat-treated product. Here we used a 9.5\% silicate clay (ARGI-2000 from VICAR, S.A.) [22] as inorganic binder, $2.5 \%$ glycerine as both plasticizer and defloculating, $1.9 \%$ methylcellulose as agglomerant, and $0.3 \%$ aluminum phosphate dissolved in o-phosphoric acid as dispersant (weight percentages referred to the extrudable coal-based paste excluding water). All the components of the paste were well premixed to ensure homogeneity. The plastic properties of the extrudable dough were a liquid limit of $47 \%$ and a plasticity index of $24 \%$, parameters defined and measured according to previous references [21]. After extrusion the green monoliths were dried at $80^{\circ} \mathrm{C}$ overnight and submitted to pre-oxidation (air, $250^{\circ} \mathrm{C}, 24 \mathrm{~h}$ ), carbonization $\left(\mathrm{Ar}, 840^{\circ} \mathrm{C}, 1 \mathrm{~h}\right)$ and finally activation $\left(\mathrm{H}_{2} \mathrm{O}, 250 \mathrm{Torr} / \mathrm{Ar}\right.$, $860{ }^{\circ} \mathrm{C}$ up to a burn-off degree of $15 \%$ ). The resulting honeycomb monoliths had the following geometric characteristics: square section, 13.7 cells $/ \mathrm{cm}^{2}, 0.08 \mathrm{~cm}$ of wall thickness, a geometric surface area of $10.4 \mathrm{~cm}^{2} / \mathrm{cm}^{3}$ with $49 \%$ open frontal area, and $5 \mathrm{~cm}$ of length.

Regarding the metal precursor, $\mathrm{Cu}\left(\mathrm{NO}_{3}\right)_{2} \cdot 3 \mathrm{H}_{2} \mathrm{O}$ from PANREAC, S.A. with $99 \%$ of purity was employed. The copper catalysts were prepared by immersing the carbon honeycomb monoliths in approx. $100 \mathrm{~mL}$ of a $1 \mathrm{M}$ aqueous solution of the above salt for $30 \mathrm{~min}$. The resulting impregnated samples were dried either conventionally (in an oven at $90{ }^{\circ} \mathrm{C}$ overnight) or using microwaves $(500 \mathrm{~W}, 1 \mathrm{~min})$. After this an activation treatment consisting in flowing $\mathrm{He}$ at $250{ }^{\circ} \mathrm{C}$ for $1 \mathrm{~h}$ was applied in order to decompose the metal precursor and obtain an active metal phase. This treatment was adopted according to thermogravimetric analysis (TGA) and Temperature-Programmed Decomposition (TPD) and Oxidation (TPO) experiments followed by mass spectrometry (results not shown). The final catalysts were named $\mathrm{Cu} / \mathrm{C}-\mathrm{C}$ and $\mathrm{Cu} / \mathrm{C}-\mathrm{m}$ in accordance with the type of drying followed. 


\subsection{Catalysts characterization}

The copper content in the catalysts was determined by ICP using a Thermo Elemental IRIS Intrepid instrument.

Textural characterization of the catalysts was carried out by $\mathrm{N}_{2}$ physisorption at $-196{ }^{\circ} \mathrm{C}$, using a Micromeritics ASAP 2020. The analysis was carried out over small pieces of crushed monoliths which were first subjected to a heating treatment under high vacuum at $350^{\circ} \mathrm{C}$ for $1 \mathrm{~h}$.

$\mathrm{X}$-ray Diffraction (XRD) analyzes were performed at room temperature on a Bruker D8 Advance powder diffractometer operating with $\mathrm{Cu} \mathrm{K}_{\alpha}$ radiation (scanning steps of $0.05^{\circ}$, counting time of $18 \mathrm{~s}$ ). In order to analyze the phases composition of the samples, the Socabim "EVA" software (9.0 version) with the "ICD PDF-2" database (release 2003) was used. Complementary analysis was performed by using the Fullprof Rietveld program [23] to simulate the XRD spectra, assuring in this way the correct identification of the phases. To achieve this, the crystallographic data of the suspected to be present phases were chosen from the Inorganic Chemistry Structural Database (ICSD) or from the Crystallographic Open Database (COD) (http://www.crystallography.net/) and introduced in the control file of Fullprof to perform the XRD simulation by refining their scales and broadening peaks parameters. Phases giving when summed up the best statistical fitting were finally chosen for the XRD spectra simulation, obtaining a deconvolution of the spectra phases and an assured phases identification.

XPS was performed on a Kratos Axis Ultra ${ }^{\text {DLD }}$ instrument, equipped with monochromatised $\mathrm{Al} \mathrm{K \alpha}(h v=1486.6 \mathrm{eV})$ radiation. $\mathrm{X}$-ray power was set to $150 \mathrm{~W}$, the analysis area was $300 \times$ $700 \mu \mathrm{m}^{2}$. Small fragments of the monoliths, before and after the reaction cycle, were analyzed without any further treatment. Spectra were recorded in FAT mode (Fixed Analyser Transmission), with a $160 \mathrm{eV}$ pass energy for the low resolution wide range spectra, and $20 \mathrm{eV}$ pass energy for high resolution spectra. Charging effects, due to the poorer electrical contact between the monolithic pieces and the holder in comparison with powdered samples, were compensated with the aid of the Kratos coaxial neutralization system. Binding energy scale was then corrected with respect to $C 1$ s adventitious carbon set at $284.8 \mathrm{eV}$. Data analysis was performed with CasaXPS version 2.3.17dev6.3a (Neal Fairley, Casa Software Ltd, 2013).

Raman spectra of the samples were measured at $5 \mathrm{~cm}^{-1}$ resolution using a confocal dispersive Raman spectrometer (Jasco, model NRS-7200). A $100 \times$ objective coupled to a $532 \mathrm{~nm} \mathrm{Nd-YAG} \mathrm{laser}$ was used as excitation source, operating at $5 \mathrm{~mW}$ power. Raman mapping was performed over $10 \times 10 \mu \mathrm{m}^{2}$ area on the samples. Individual spectra were collected for $60 \mathrm{~s}$. Spectra were corrected for fluorescence background applying a wide bandwidth correction procedure.

TPR experiments were performed employing a Thermostar QMS200 (Pfeiffer) mass spectrometer with a $60 \mathrm{~mL} / \mathrm{min}$ flow of $\mathrm{H}_{2}(5 \%) /$ Ar, using also milled pieces of monoliths $(50 \mathrm{mg})$ and $10^{\circ} \mathrm{C} / \mathrm{min}$ as heating rate.

Finally, SEM images and EDS data were obtained using a Quanta 200 scanning electron microscope (Philips) equipped with a Phoenix Microanalysis system using a nominal resolution of $3 \mathrm{~nm}$.

\subsection{Activity testing}

All reagents were purchased from Aldrich or PANREAC and were used without further purification. The reactions were performed in a Radleys carousel under open atmosphere.

\subsubsection{General procedure for the Kharasch-Sosnovsky allylic oxidation} of cyclohexene

The crushed catalyst ( $60 \mathrm{mg}$ ) was suspended in $\mathrm{CH}_{3} \mathrm{CN}(4 \mathrm{~mL})$ in a $50 \mathrm{~mL}$ round bottom flask. The carboxylic acid $(1.0 \mathrm{mmol})$ was then added and it was vigorously stirred for $10 \mathrm{~min}$. Cyclohexene $(4 \mathrm{mmol}, 408 \mu \mathrm{L})$ and $t-\mathrm{BuOOH}(1.5 \mathrm{mmol}, 193 \mu \mathrm{L}$ of a $70 \%$ solution in water) were added. The mixture was stirred at $82^{\circ} \mathrm{C}$. After $24 \mathrm{~h}$, saturated aqueous $\mathrm{Na}_{2} \mathrm{SO}_{3}$ solution $(10 \mathrm{~mL})$ was added. The solution was then extracted with EtOAc $(3 \times 10 \mathrm{~mL})$, washed with saturated aqueous EDTA solution $(10 \mathrm{~mL})$ and dried over anhydrous $\mathrm{Na}_{2} \mathrm{SO}_{4}$. The solvent was removed under vacuum and the resulting residue was purified by silica gel column chromatography employing a 5:95 mixture of EtOAc/hexanes as eluent.

\subsubsection{General procedure for the Kharasch-Sosnovsky allylic oxidation of cyclohexene employing the honeycomb monoliths}

To ensure the recirculation of the reaction mixture along the monolith, the reaction was run in a Thiele tube with magnetic stirring. $\mathrm{CH}_{3} \mathrm{CN}(30 \mathrm{~mL})$ was poured into the Thiele tube. The monolith was then immersed in the wider arm of the tube. Benzoic acid (10 mmol, $1.22 \mathrm{~g}$ ), cyclohexene (40 mmol, $4.08 \mathrm{~mL})$, and $t-\mathrm{BuOOH}$ ( $15 \mathrm{mmol}, 1.93 \mathrm{~mL}$ of a $70 \%$ solution in water) were added. The reaction was heated to a gentle boil. The reaction was monitored at 4,6 and $24 \mathrm{~h}$ by GC. After $24 \mathrm{~h}$, the reaction was worked up and the product purified as described above. The monolith was recovered, thoroughly washed with acetonitrile, and left to dry prior to the following cycle. Fig. 1 illustrates the set up in the case of an experiment carried out with an entire monolith.

The products were identified by Nuclear Magnetic Resonance (NMR) using an Agilent 400 MR instrument. GC analyzes were performed in a Perkin-Elmer Clarus 400 chromatograph using a DB-5 column. Octadecane was employed as internal standard.

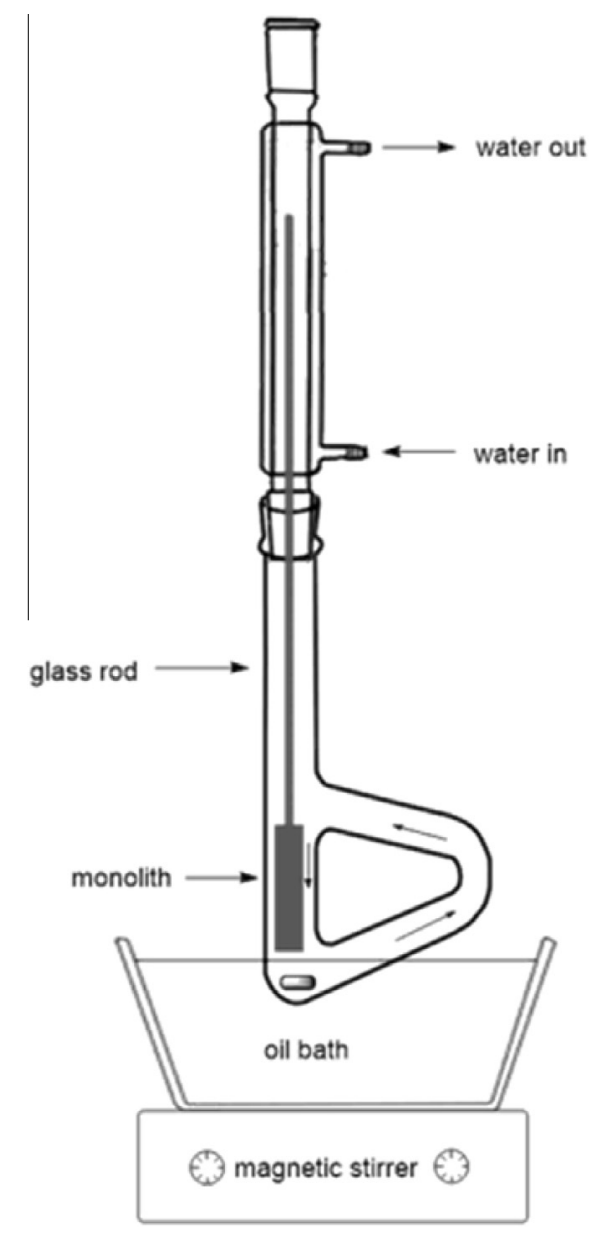

Fig. 1. Scheme of the experimental set up in the catalytic tests performed using entire monoliths in the allylic oxidation of cyclohexene 


\section{Results and discussion}

\subsection{Compositional and textural characterization of the catalysts}

Results obtained by ICP analysis of the investigated catalysts are shown in Table 1. It can be observed that the amount of copper introduced over the $\mathrm{Cu} / \mathrm{C}-\mathrm{m}$ carbon honeycomb monoliths is approximately twice as much as that of $\mathrm{Cu} / \mathrm{C}-\mathrm{C}$. On this regard, it should be considered that according to the weight of equal dimensioned pieces the former had lower density (around 25\%). The origin of such difference might be attributed to the partial burning of carbon in the $\mathrm{Cu} / \mathrm{C}-\mathrm{m}$ samples already initiated with the metal precursor decomposition and induced by the microwaves treatment. The loss of carbon would imply a relative increase of the copper content.

Table 1 also reports the results of the textural characterization by means of $\mathrm{N}_{2}$ physisorption. The registered isotherms (not shown) were in both samples type-I characteristic of materials having micropores, textural feature already observed in the bare carbon support here used [2,3]. The decrease of both BET specific surface area and pore volume in the copper-containing samples compared with the bare support must be due to the covering of the carbon surface by the deposited copper phase. Fig. 2 provides additional details about how the pore structure of the support is modified by the copper phase deposition as function of the preparative procedure. Note that conventional drying leads to a loss of pores in the whole range of sizes studied while the use of microwaves especially hinders mesoporosity. The relative difference between $\mathrm{Cu} / \mathrm{C}-\mathrm{c}$ and $\mathrm{Cu} / \mathrm{C}-\mathrm{m}$ could be related to both differences in the dispersion reached for the copper phases and in the content of undecomposed precursor residues. On this regard, although thermal analysis performed over crushed monoliths in quartz low volume reactors recommended the activation treatment applied for the precursor decomposition, some deviation in the results obtained using bigger reactors which allow the treatment of entire monoliths cannot be discarded. The latter experimental conditions might imply mass and/or heat transfer problems and reduce the expected effect of heating.

\subsection{SEM-EDS study}

The SEM technique reveals significant differences between the two catalysts prepared at the micron-sized level. The set of images obtained, a selection of which is shown in Fig. 3, might help to understand how the copper phase is supported on the monoliths. Considering that particles with bright contrast correspond to the metal phase, as confirmed by means of the EDS probe coupled with the electron microscope, notice the different aspect and bigger size of these particles in $\mathrm{Cu} / \mathrm{C}-\mathrm{c}$ in relation to $\mathrm{Cu} / \mathrm{C}-\mathrm{m}$.

Mapping by EDS allows getting clearer evidence of the more homogeneous distribution and higher dispersion at micron level of copper for the microwaves dried catalyst in good agreement with previous studies reported for other monolithic supports

Table 1

Summary of main results obtained in the chemical and textural characterization of the catalysts.

\begin{tabular}{lllll}
\hline Sample & $\mathrm{Cu}($ wt.\%) & $S_{\mathrm{BET}}\left(\mathrm{m}^{2} / \mathrm{g}\right)$ & Pore vol. $(\mathrm{ml} / \mathrm{g})$ & Micropore vol. $(\mathrm{ml} / \mathrm{g})^{\mathrm{b}}$ \\
\hline $\mathrm{Cu} / \mathrm{C}-\mathrm{c}$ & $2.16 \pm 0.07$ & 200 & 0.104 & 0.090 \\
$\mathrm{Cu} / \mathrm{C}-\mathrm{m}$ & $4.73 \pm 0.10$ & 451 & 0.213 & 0.170 \\
Support & - & 521 & 0.274 & 0.195
\end{tabular}

\footnotetext{
a As measured by ICP-AES analysis.

b As estimated by means of $t$-plot (Harkins-Jura) analysis from $\mathrm{N}_{2}$ physisorption data.
}

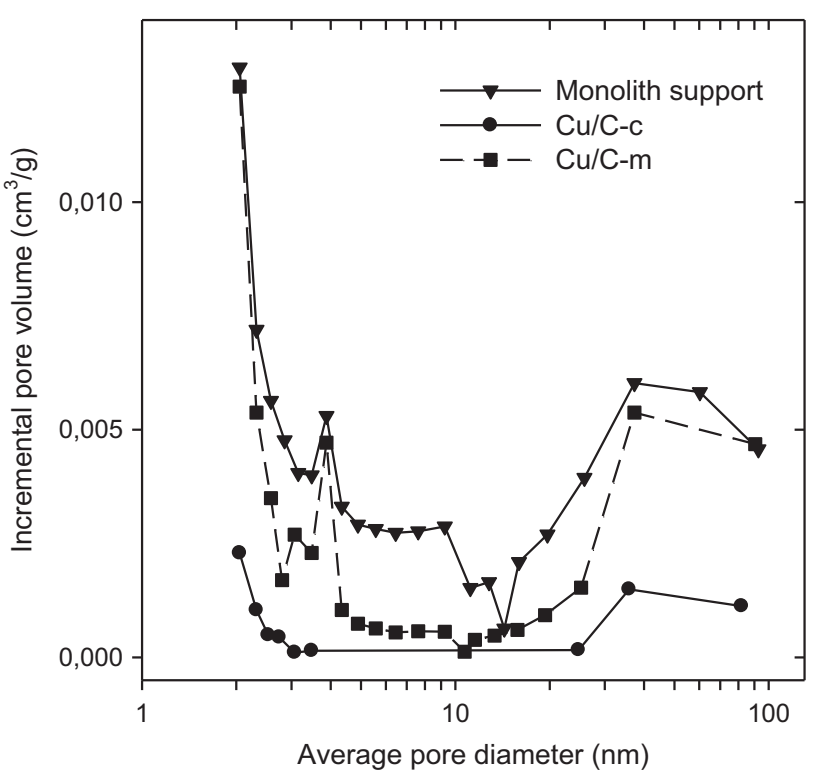

Fig. 2. Pore size distribution curves as obtained from $\mathrm{N}_{2}$ physisorption at $-196{ }^{\circ} \mathrm{C}$ (adsorption branch) on the studied samples.

[24]. Elemental mapping of metal phase in the $\mathrm{Cu} / \mathrm{C}-\mathrm{c}$ and $\mathrm{Cu} / \mathrm{C}-$ $\mathrm{m}$ catalysts shown also in Fig. 3 demonstrates that copper is present as large aggregates in the former while it is more evenly spread in the latter. Heterogeneity of the metal distribution in the $\mathrm{Cu} / \mathrm{C}-\mathrm{c}$ catalyst must be a consequence of copper migration during the drying step in the preparation of this sample. As a matter of fact, a simple visual observation allowed detecting light blue stains denotative of higher metal concentration at different parts of the monoliths, especially at the borders. This effect might be not operating in the $\mathrm{Cu} / \mathrm{C}-\mathrm{m}$ catalyst due to the quicker drying achieved with the use of microwaves.

The EDS technique has also allowed detecting in both monoliths the presence of minor amounts of both metallic ( $\mathrm{Al}, \mathrm{K}, \mathrm{Ca}, \mathrm{Fe}, \mathrm{Ti}$ ) and pseudo and non-metallic elements (Si, P, S) in good agreement with the presence of ashes in the starting carbon material and the use of additives for its further extrusion. Nevertheless, its possible influence can be ignored as activity of the carbon support alone in the allylic oxidation investigated was negligible (see below).

\subsection{XRD study with Rietveld analysis}

The XRD data were analyzed using both the EVA software, for phase identification, and the Fullprof program for simulation. This analysis reveals the high complexity of the structural composition of the catalysts. As an example, Figs. 4 and 5 show the experimental diffractograms recorded for $\mathrm{Cu} / \mathrm{C}-\mathrm{c}$ and $\mathrm{Cu} / \mathrm{C}-\mathrm{m}$ catalysts respectively along with their deconvolution into different phases as deduced with the Rietveld program [25]. Fig. 6 shows the small difference between the experimental spectra and those simulated by mixtures of phases proposed by the EVA software. Estimate of the average crystal size as an indication of the grade of dispersion reached by copper was also performed.

A comparative analysis of results shown in Figs. 4 and 5 points to a significantly different scenario for the copper-related phases present in the catalysts investigated. In both of them $\mathrm{Cu}(0)$ was detected but it should be noticed that in $\mathrm{Cu} / \mathrm{C}-\mathrm{m}$ bigger copper particles were detected in a bimodal distribution: $380 \AA$ Aiameter particles with a lattice parameter close to that of $\mathrm{Cu}(3.61727 \AA$ ), and $180 \AA \mathrm{Cu}$ particles with a bigger lattice parameter (3.68133 $\AA$ ). For $\mathrm{Cu} / \mathrm{C}$-c a unimodal distribution of smaller particles 

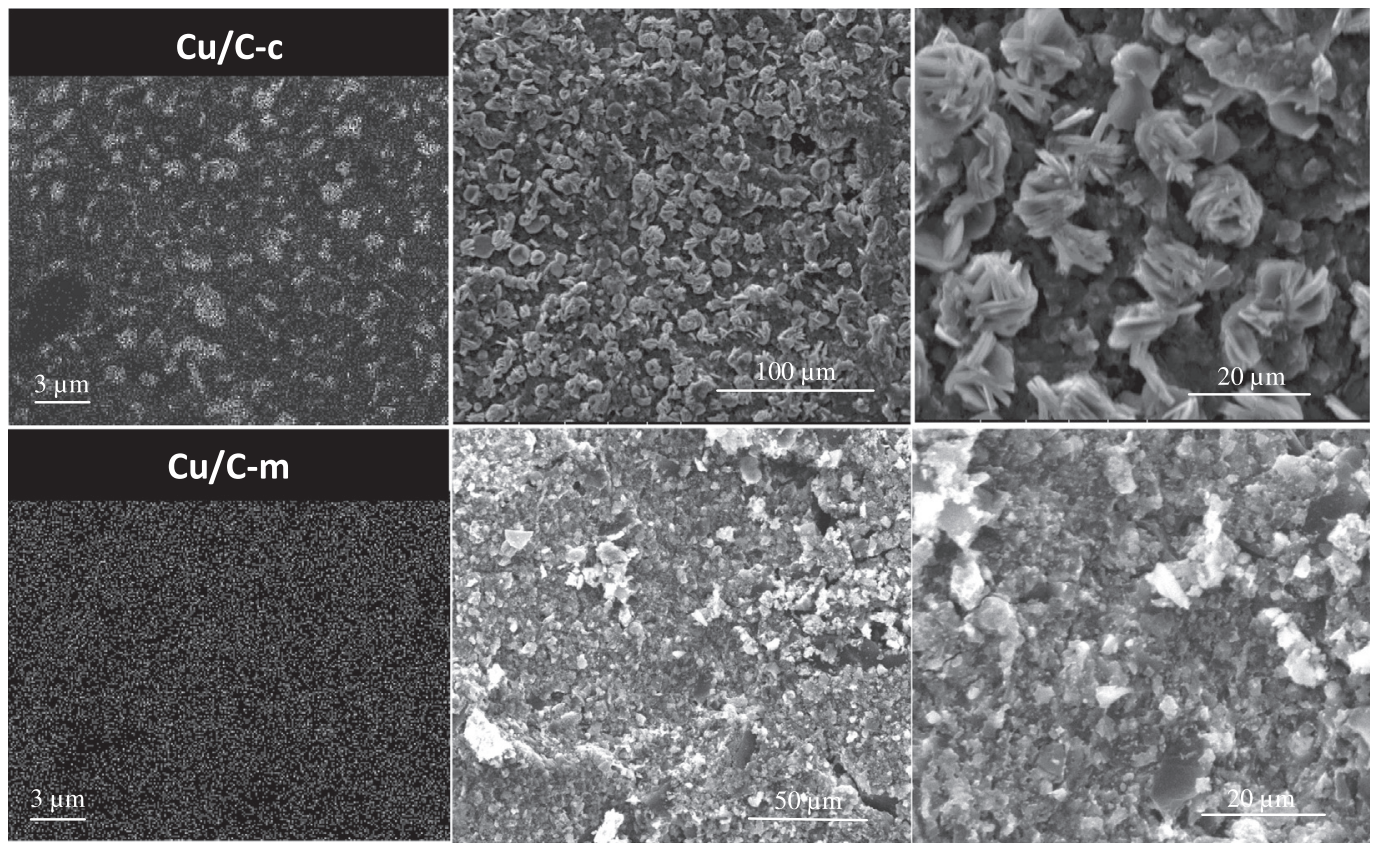

Fig. 3. Scanning electron micrographs and copper (bright spots) distribution as obtained by EDS mapping of the carbon monolith-supported copper catalysts.

(40 A) was tentatively detected, with an intermediate lattice parameter $(3.63805 \AA)$. Also remarkable, $\mathrm{Cu}(\mathrm{I})$ in the form of $\mathrm{Cu}_{2} \mathrm{O}$-cuprite $(260 \AA)$ was only observed in $\mathrm{Cu} / \mathrm{C}-\mathrm{m}$. By contrast, although $\mathrm{Cu}\left(\mathrm{NO}_{3}\right)_{2}$ was detected in both $\mathrm{Cu} / \mathrm{C}-\mathrm{m}$ and $\mathrm{Cu} / \mathrm{C}-\mathrm{c}$, the analysis also revealed the presence of another nitrate phase (gerhardtite, $\mathrm{Cu}_{2}(\mathrm{OH})_{3} \mathrm{NO}_{3}, 580 \AA$ ) in the latter. Summarizing, all these findings suggest that the way of drying used in the catalyst preparation is a key parameter for defining the final redox state of the active phase. In particular, the use of microwaves seems to help the copper reduction while conventional drying tends to stabilize the $\mathrm{Cu}(\mathrm{II})$ species. In this respect, one should consider the slightly higher temperatures which can be reached during the drying step when using microwaves (approximately $120^{\circ} \mathrm{C}$ instead of $90^{\circ} \mathrm{C}$ ).

\subsection{TPR investigation}

In an effort to confirm the conclusions derived from the XRD study, TPR experiments were carried out regarding their particular sensitiveness to the metal phase nature. The $m / e 18$ signal corresponding to the water formation mainly associated with the $\mathrm{H}_{2}$ consumption and consequent reduction of the copper phases in the catalyst is presented in Fig. 7. For comparative purposes signals obtained in the same kind of experiments performed with monolith support only and during TPR of a $\mathrm{CuO}$ reference sample are also included.

Notice that the double peak detected in the latter can be reasonably attributed to reduction in two steps from the $2+$ oxidation state to the 0 in copper, passing through the $1+$ state [26]. When compared with the support it is clear that the major difference given by TPR for the copper-containing samples is observed in the range of moderate temperatures below $500^{\circ} \mathrm{C}$ and might correspond to the reduction of $\mathrm{Cu}$ species including oxides and nitrates. Nevertheless notice the difference between traces corresponding to $\mathrm{Cu} / \mathrm{C}-\mathrm{c}$ and $\mathrm{Cu} / \mathrm{C}-\mathrm{m}$ in that range. The former presents a profile which is more similar to that of the pure support while the latter resembles that of $\mathrm{CuO}$. In spite of the complexity of the analysis [26], two observations should be highlighted. First, the peak around $300{ }^{\circ} \mathrm{C}$ which is only observed in $\mathrm{Cu} / \mathrm{C}-\mathrm{m}$, which suggests the presence of $\mathrm{Cu}_{2} \mathrm{O}$ in this catalyst, in good agreement with results deduced by Rietveld analysis. Second, in $\mathrm{Cu} / \mathrm{C}-\mathrm{c}$ the oxidized copper species must be stabilized taking into account the high temperature necessary for their reduction in hydrogen atmosphere.

\subsection{Catalytic activity of the carbon monolith-supported copper catalysts}

Table 2 presents the exploratory screening results obtained in the Kharasch-Sosnovsky allylic oxidation of cyclohexene as a function of the carboxylic acid employed. For this study the copper coated honeycomb monoliths were crushed and the reaction was performed in batch mode with the catalyst (well stirred) in suspension. It is remarkable that both catalysts prepared in this work afforded the corresponding allylic esters, although the performance of the $\mathrm{Cu} / \mathrm{C}-\mathrm{c}$ catalyst proved to be superior. Also noteworthy, the carbon support alone did not show activity.

Once demonstrated the potential of the catalyst in the above reaction, a second type of experiment was designed. It consisted on using entire impregnated monoliths and checking their stability after consecutive reaction cycles of $24 \mathrm{~h}$ using the benzoyloxylation of cyclohexene as a benchmark reaction. This operation mode allows a simpler separation of the catalyst from the reaction medium. This means that the products were removed and the reactor reloaded with new substrates and additives after each cycle. In addition the activity was measured at intermediate times for a better follow up. Table 3 summarizes main data obtained in this study. As a reference, the result obtained with the monolithic carbon support is also included.

As can be seen, the $\mathrm{Cu} / \mathrm{C}$-c catalyst is very stable, still reaching maximum activity even after 4 cycles. It is also noticeable the good mechanical resistance of this monolith, as indicated by the small weight loss at the end of the experiment. These results contrast with those of $\mathrm{Cu} / \mathrm{C}-\mathrm{m}$. In this case the monolith broke before the end of the first cycle and the yield measured after different reaction times evidenced to be lower than the respective values of $\mathrm{Cu} / \mathrm{C}-\mathrm{c}$. The lower mechanical resistance of the $\mathrm{Cu} / \mathrm{C}-\mathrm{m}$ monolith could be reasonably related to its higher porosity (consistent with its lower 




Fig. 4. Experimental $\mathrm{X}$-ray diffractogram of the fresh $\mathrm{Cu} / \mathrm{C}$-c catalyst and phases used to simulate it with Fullprof, after adjustment. ${ }^{*}$ It can be either $\mathrm{AlPO}_{4}$ or $\mathrm{SiO}_{2}$, due to the isoelectronic character of $\mathrm{Al}^{3+}, \mathrm{Si}^{4+}$ and $\mathrm{P}^{5+}$, and because both phases have the same lattice parameters.

density, above commented) if compared to $\mathrm{Cu} / \mathrm{C}-\mathrm{c}$ (see Table 1 ). Previous studies with carbon-based monoliths demonstrated the inverse relationship between porosity and resistance [5].

All the characterization results so far discussed pointed to a positive effect of the microwaves drying of the catalyst as it seems to induce better textural properties, higher degree of decomposition of the copper precursor and higher active phase homogeneity and dispersion. Paradoxically, these results do not lead to higher activity in the allylic oxidation of cyclohexene. On the contrary, $\mathrm{Cu} / \mathrm{C}-\mathrm{c}$ was found to be the catalyst showing the best performance in this reaction. This means that the catalytic activity must be controlled by other parameters. In this sense a detailed XPS and Raman study was also carried out.

\section{6. $X P S$ results}

As Kharasch and Sonovsky reported long time ago [27,28], allylic oxidation of alkenes to give racemic allylic esters seems to have a mechanism which imply, in the case of copper catalysts, that the metal center is intimately involved in the $\mathrm{C}-\mathrm{O}$ bond forming step through an allyl cuprate intermediate [11]. Such radical mechanism could be facilitated by the direct presence of $\mathrm{Cu}(\mathrm{II})$ species as long as $\mathrm{Cu}(0)$ or $\mathrm{Cu}(\mathrm{I})$ would need previous oxidation.

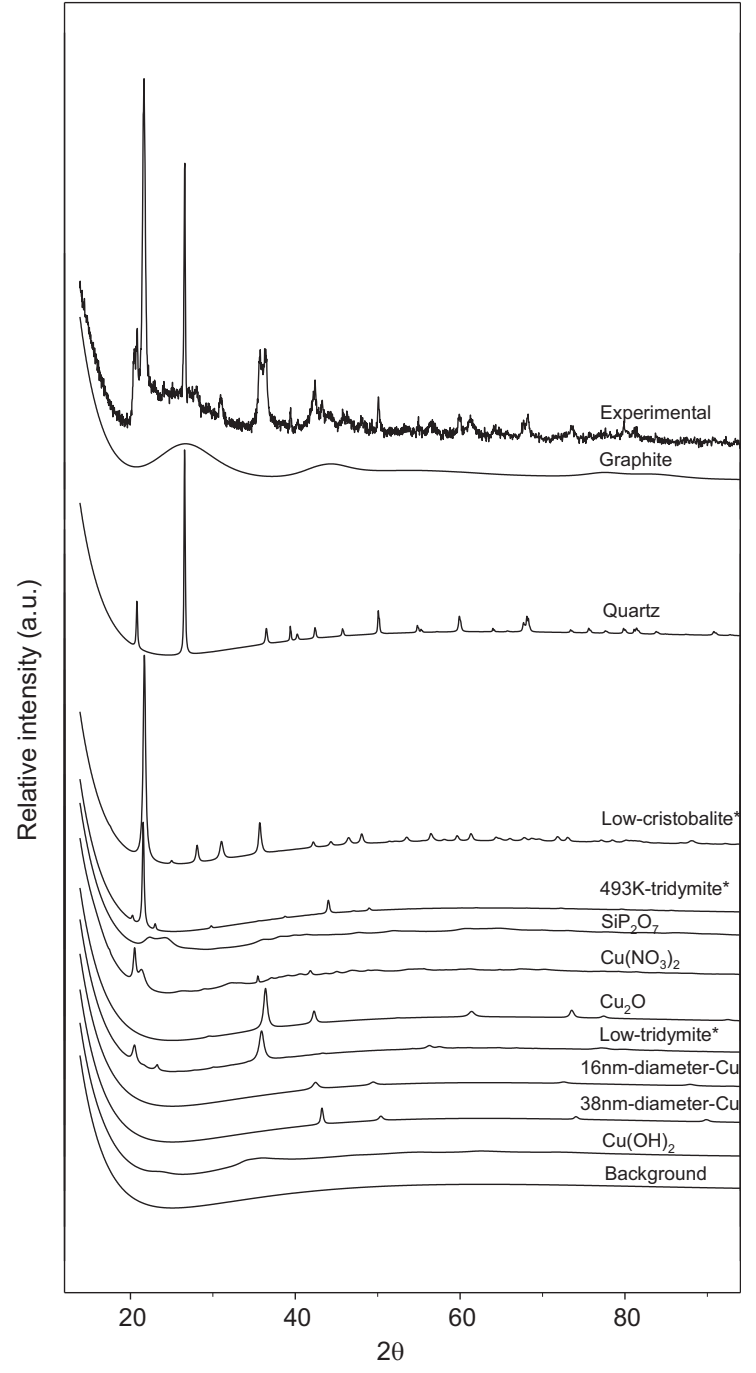

Fig. 5. Experimental $X$-ray diffractogram of the fresh $\mathrm{Cu} / \mathrm{C}-\mathrm{m}$ catalyst and phases used to simulate it with Fullprof, after adjustment. "It can be either $\mathrm{AlPO}_{4}$ or $\mathrm{SiO}_{2}$, due to the isoelectronic character of $\mathrm{Al}^{3+}, \mathrm{Si}^{4+}$ and $\mathrm{P}^{5+}$, and because both phases have the same lattice parameters.

In this sense, considering XRD and TPR results above discussed, the higher stabilization of $\mathrm{Cu}(\mathrm{II})$ species in $\mathrm{Cu} / \mathrm{C}-\mathrm{c}$ might precisely become an advantage for its performance respect to $\mathrm{Cu} / \mathrm{C}-\mathrm{m}$. Nevertheless information provided by both techniques should be taken with care as it is related to the whole mass of the samples.

For this reason the catalysts were also studied by XPS. This technique is particularly sensitive to the presence of $\mathrm{Cu}$ (II) on the surface which is actually where reaction takes place. Moreover, XPS can be ideal to investigate the spent catalysts in order to better understand the causes of deactivation in the course of reaction.

Figs. 8-10 show respectively the $\mathrm{Cu} 2 \mathrm{p}, \mathrm{N} 1 \mathrm{~s}$ and $\mathrm{C} 1 \mathrm{~s}$ signals obtained by XPS for $\mathrm{Cu} / \mathrm{C}-\mathrm{c}$ and $\mathrm{Cu} / \mathrm{C}-\mathrm{m}$, both fresh and after the last reaction cycle followed in each case in the catalytic stability tests (Section 3.5). Hereafter the word "post" will be added to the name of the catalyst to denote we are referring to the used samples.

On the other hand, Table 4 summarizes the main results derived from the analysis of the above signals. Estimate of the $\mathrm{Cu}$ (II) content was performed according to previous studies on coppercontaining materials $[29,30]$, while deconvolution of the N1s and C1s signals was possible following other references [31-33]. Finally, Table 5 shows the general elemental surface composition as deduced from the analysis of the high resolution XPS spectra. 



Fig. 6. (a) Fullprof simulation of XRD data, using the above mentioned phases; (b) difference between experimental and simulated spectra. Up and low graphs correspond to $\mathrm{Cu} / \mathrm{C}-\mathrm{c}$ (goodness of fit $\left(\chi^{2}\right)$ : 1.50) and $\mathrm{Cu} / \mathrm{C}-\mathrm{m}$ (goodness of fit $\left.\left(\chi^{2}\right): 1.67\right)$, respectively.

The first result worthy of comment is that copper is fully oxidized as $\mathrm{Cu}(\mathrm{II})$ on the surface of both catalysts investigated (Fig. 8 and Table 4). Nevertheless the XPS technique allows distinguishing subtle differences regarding the environment of copper ions. Thus while XPS spectrum of $\mathrm{Cu} / \mathrm{C}-\mathrm{C}$ matches that reported in literature for $\mathrm{CuO}$, the one corresponding to $\mathrm{Cu} / \mathrm{C}-\mathrm{m}$ can be rather assigned to $\mathrm{Cu}(\mathrm{OH})_{2}[29,30]$. This finding is significant as it could be at the root of the higher activity of the conventionally dried sample (above section). Understanding the different influence of $\mathrm{O}^{2-}$ and $\mathrm{OH}^{-}$anions surrounding $\mathrm{Cu}^{2+}$ cations on the catalytic activity here presented is certainly a hard task. To our knowledge no data on the mechanism in heterogeneous conditions for the reaction have been reported yet. Moreover, even decades after the original works by Kharasch and Sosnovsky $[27,28]$ the



Fig. 7. TPR diagrams showing $\mathrm{H}_{2} \mathrm{O}(\mathrm{m} / \mathrm{e}$ 18) formation denotative of reduction in the studied samples. That corresponding to a $\mathrm{CuO}$ sample is also included as a reference.

mechanism in homogenous medium is considered quite intricate. Recently, Salvatella et al. have performed a complete study of an enantioselective version of the reaction employing B3LYP/6-31G* calculations, using a chiral bisoxazoline-copper (I) complex [34]. The mechanism involves a copper (III) complex as an intermediate, which undergoes a haptotropic rearrangement, leading to scrambling between vinylic and allylic positions. In any case, there is no doubt that the presence of different species in the environment affects the outcome of the reaction. For instance, Komiya et al. reports that the catalytic activity of copper salts in alkene oxidation reactions is dependent of the electron donating capacity of the counterion of the copper source [35].

Another XPS result worthy of comment is that a slight decrease of the relative surface content of $\mathrm{Cu}(\mathrm{II})$ is observed upon reaction in both catalysts (Table 4 ). This result is consistent with other authors observations [36] who reported on the key role of carbonaceous species in the reduction of $\mathrm{Cu}^{2+}$ to $\mathrm{Cu}^{+}$in $\mathrm{Cu}-\mathrm{ZSM}-5$ catalysts. In parallel, the relative total content of copper also diminishes in both catalysts after the reaction (see Table 5). Considering that copper must be the active phase for the reaction, this disappearance might explain the deactivation observed for $\mathrm{Cu} / \mathrm{C}-\mathrm{c}$ in the fifth cycle (Table 3). According to literature [37,38], leaching effects have been observed in similar reactions performed over transitionmetals supported catalysts. However, in our case, an ICP chemical analysis of the catalysts after the reaction did not reveal any copper loss. Deposition of carbonaceous species generated in the course of reaction could also explain that the percentage of $\mathrm{Cu}$ detected by XPS diminishes. In this sense, note in Table 5 that along with an increase in the carbon content of the "post" samples, a decrease of other elements originally present on the surface also occurs. This is the case of $\mathrm{N}$ which might reasonably proceed from the nitrate copper precursor, but also of $\mathrm{O}$ mainly related to the preoxidized state of the carbon monolith support in accordance with its preparation (see Section 2).

An additional interesting observation derived from XPS comes from observing Fig. 9. Analysis of the N1s signal reveals that on a surface level both catalysts present nitrates which evolved to reduced forms upon reaction. From a quantitative viewpoint strong similarities are found for both catalysts concerning this element 
Table 2

Allylic oxidation of cyclohexene over the crushed monolithic catalysts using different carboxylic acids. ${ }^{a}$

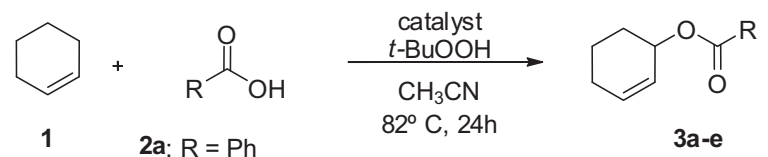

$$
\begin{aligned}
& \text { 2b: } \mathrm{R}=4-\mathrm{ClC}_{6} \mathrm{H}_{5} \\
& \text { 2c: } \mathrm{R}=4-\mathrm{OMeC}_{6} \mathrm{H}_{5} \\
& \text { 2d: } \mathrm{R}=\mathrm{CH}_{2} \mathrm{C}_{6} \mathrm{H}_{5} \\
& \text { 2e: } \mathrm{R}=\mathrm{C}_{7} \mathrm{H}_{15}
\end{aligned}
$$

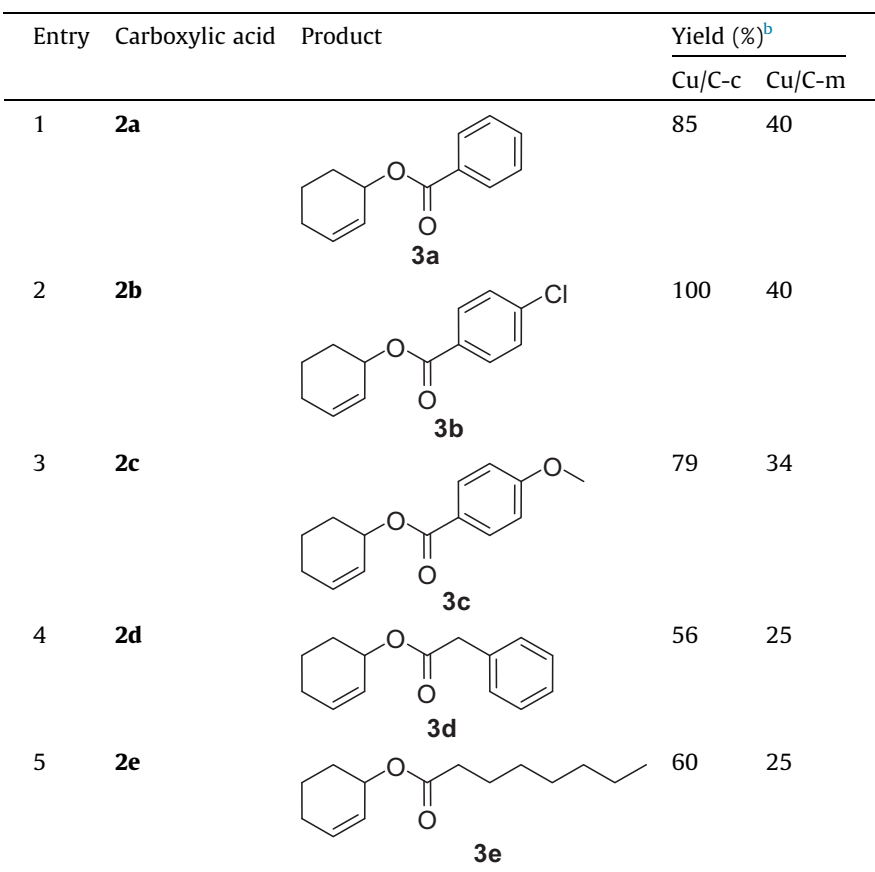

a All reactions were carried out using carboxylic acids $2 a-e(1.0 \mathrm{mmol})$, cyclohexene 1 ( $4.0 \mathrm{mmol}), t-\mathrm{BuOOH}(1.5 \mathrm{mmol}), 60 \mathrm{mg}$ of $\mathrm{Cu} / \mathrm{C}-\mathrm{c}(2.0 \mathrm{~mol} \%)$ or $60 \mathrm{mg}$ of $\mathrm{Cu} / \mathrm{C}-\mathrm{m}$ (4.5 mol\%), refluxing $\mathrm{CH}_{3} \mathrm{CN}(4 \mathrm{~mL}), 24 \mathrm{~h}$.

b GC yields.

(see Table 4). This contrasts with data from the massive techniques which suggested higher residual content of copper (II) stabilized in the form of undecomposed nitrates in $\mathrm{Cu} / \mathrm{C}-\mathrm{C}$. However, evolution of the total surface amount of $\mathrm{N}$ in relation to that of $\mathrm{Cu}$ is quite different in $\mathrm{Cu} / \mathrm{C}-\mathrm{m}$ (Table 5). While it is more parallel for both elements in $\mathrm{Cu} / \mathrm{C}-\mathrm{c}$, it shows a less relative decrease for $\mathrm{N}$ in the sample dried with microwaves. If such decrease relates to deposits on the active copper sites as consequence of the catalyzed reaction, this could be interpreted as an indication of lower vicinity of nitrate groups with regard to copper in $\mathrm{Cu} / \mathrm{C}-\mathrm{m}$.

Finally analysis of the C1s signal in Fig. 10 also deserves some comments. As also shown in Table 4, significant changes of the surface carbon phase take place upon reaction in both catalysts. Notice how the original majority graphitic component diminishes while other carbon species clearly grow. Moreover a detail perusal of these species indicates that they must be related to the allylic ester formed as main product of the reaction. This would point to the covering of copper sites by these deposits as a major cause of deactivation with time.

\subsection{Raman Spectroscopy study}

Fig. 11a illustrates a spectrum representative of the Raman results obtained for all the samples here investigated. Histograms of the values of the ratio of intensities ID/IG were determined
Table 3

Study of the stability of entire monolithic catalysts in the allylic oxidation of cyclohexene with $t$-BuOOH in the presence of benzoic acid.



\begin{tabular}{llllll}
\hline Catalyst & Cycle & $\begin{array}{l}\text { Yield 3a } \\
(4 \mathrm{~h})(\%)^{\mathrm{b}}\end{array}$ & $\begin{array}{l}\text { Yield 3a } \\
(6 \mathrm{~h})(\%)^{\mathrm{b}}\end{array}$ & $\begin{array}{l}\text { Yield 3a } \\
(24 \mathrm{~h})(\%)^{\mathrm{b}}\end{array}$ & $\begin{array}{l}\text { Weight of } \\
\text { monolith }(\mathrm{g})\end{array}$ \\
\hline $\mathrm{Cu} / \mathrm{C}-\mathrm{c}$ & 1 & 63 & 66 & 100 & 1.779 \\
& 2 & 55 & 69 & 99 & 1.782 \\
& 3 & 54 & 70 & 100 & 1.724 \\
& 4 & 50 & 67 & 100 & 1.664 \\
& 5 & 28 & 45 & 64 & 1.696 \\
& After 5th & & & & 1.647 \\
& run & & & & \\
Cu/C-m & 1 & 35 & 34 & 35 & 1.395 \\
Carbon & 1 & - & - & 2 & 1.547 \\
\hline
\end{tabular}

a All the reaction cycles were carried out immersing the monolith in a Thiele tube, using benzoic acid $\mathbf{2 a}(10 \mathrm{mmol})$, cyclohexene $\mathbf{1}(40 \mathrm{mmol}), t-\mathrm{BuOOH}$ (15 mmol), refluxing $\mathrm{CH}_{3} \mathrm{CN}(30 \mathrm{~mL})$.

b GC yields.

c The monolith only endured one cycle. A small fragment $(0.519 \mathrm{~g})$ was recovered.

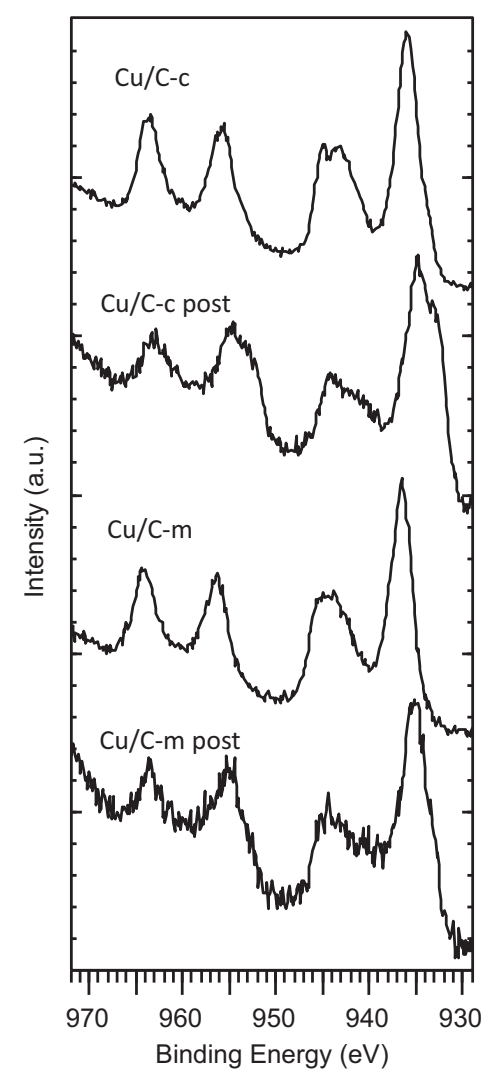

Fig. 8. Cu2p core-level spectra obtained by XPS for the fresh and spent (post) catalysts.

from the set of the Raman spectra collected in the mappings performed on the samples (Fig. 11b). Differences in the $\mathrm{Cu} / \mathrm{C}-\mathrm{C}$ and $\mathrm{Cu} / \mathrm{C}-\mathrm{m}$ monoliths can be inferred on the basis of these Raman results. The ratio of the intensities of the so-called D and $G$ bands has been proved to be a good indicator to quantify defects (or disorder) in the graphite structure [39]. The $G$ band is assigned to the scattering by graphitic optical zone center 


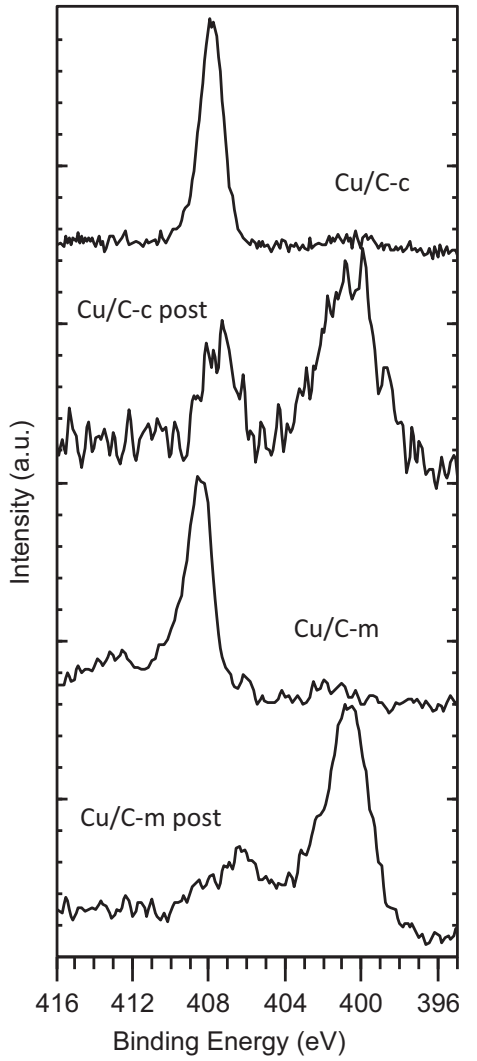

Fig. 9. N1s core-level spectra obtained by XPS for the fresh and spent (post) catalysts.

phonons and corresponds to the $E_{2 \mathrm{~g}}$ in-plane stretching mode of graphene. This band is insensitive to the wavelength of the laser excitation and polarization, and it invariably occurs at about $1583 \mathrm{~cm}^{-1}$ in graphite [40]. On the other hand, the so-called defect $D$ band is an indicator of defective structure and its position depends on the excitation laser wavelength used in Raman experiments. The $\mathrm{D}$ band is related to the breathing modes of the six-atoms rings in graphene sheets and requires a defect for its activation, which breaks the basic symmetry of the graphene sheet and is observed in $\mathrm{sp}^{2}$-carbons containing vacancies, impurities or other symmetry-breaking defects [39]. Characteristics of this Raman feature (position and intensity) are very sensitive to the nature of the defects. We have found that positions of the $\mathrm{G}$ band range between $1590 \mathrm{~cm}^{-1}$ and $1605 \mathrm{~cm}^{-1}$ for the samples under study, while the positions of the $\mathrm{D}$ band range between $1330 \mathrm{~cm}^{-1}$ and $1360 \mathrm{~cm}^{-1}$. These results suggest a significant richness in the nature of the carbons present in the samples, as well as in the fraction of $\mathrm{sp}^{2}$ and $\mathrm{sp}^{3}$ carbons.

We have also found that the Probability Density Functions (PDF) of the ID/IG ratio values is sharp in the case of the $\mathrm{Cu} / \mathrm{Cu}-\mathrm{C}$ monolith and wider in the case of the $\mathrm{Cu} / \mathrm{Cu}-\mathrm{m}$ monolith (Fig. 11c). Also, central value is smaller for the former and larger for the latter. These results point towards a more defective (or disordered) structure in the $\mathrm{Cu} / \mathrm{C}-\mathrm{m}$ monolith, in comparison with the $\mathrm{Cu} / \mathrm{C}-\mathrm{c}$ monolith. Values of the ID/IG ratio have been reported to increase when increasing the activation of activated carbon [41]. In this respect our results are consistent with the higher effective area found by physisorption in the $\mathrm{Cu} / \mathrm{C}-\mathrm{m}$ monolith, in comparison with the $\mathrm{Cu} / \mathrm{C}-\mathrm{c}$ monolith. Therefore, a higher activation, as well as a larger $\mathrm{sp}^{3}$ carbon content, seems to be inferred from these results for the $\mathrm{Cu} / \mathrm{C}-\mathrm{m}$ monolith in comparison with the $\mathrm{Cu} / \mathrm{C}-\mathrm{c}$ monolith. In

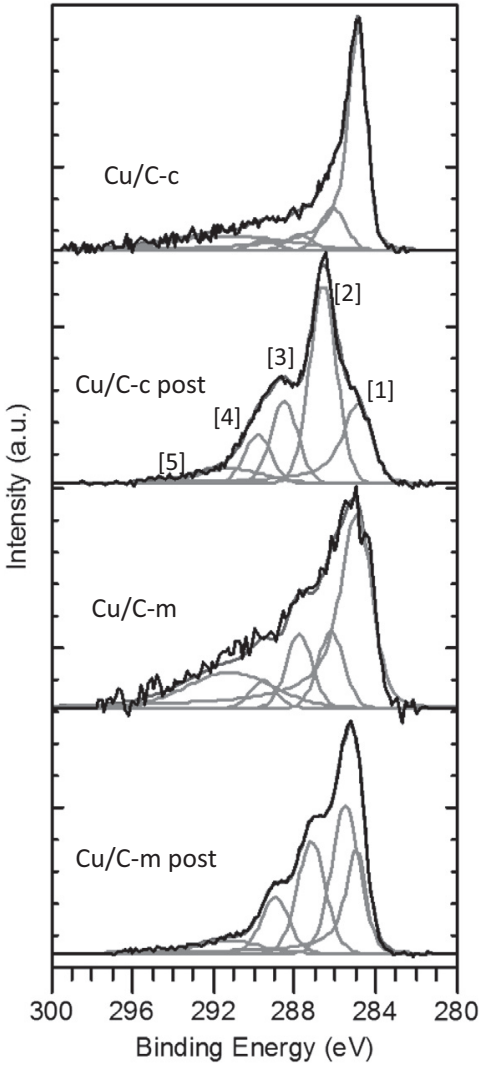

Fig. 10. C1s core-level spectra obtained by XPS and fitted curves of the fresh and spent (post) catalysts. Peak position corresponding to [1] graphitic or aliphatic [2] $-\mathrm{C}-\mathrm{O}-$, [3] $\mathrm{C}=\mathrm{O}$, and [4] $-\mathrm{C}-\mathrm{O}-\mathrm{O}-$ species, and to [5] $\pi-\pi^{*}$ transition associated to [1], is indicated.

Table 4

Data obtained by analysis of the main XPS signals.

\begin{tabular}{|c|c|c|c|c|c|c|c|}
\hline \multirow[t]{2}{*}{ Sample } & \multirow{2}{*}{$\begin{array}{l}\mathrm{Cu} 2 \mathrm{p} \\
\% \mathrm{Cu}(\mathrm{II})\end{array}$} & \multicolumn{4}{|l|}{$\mathrm{C} 1 \mathrm{~s}$} & \multicolumn{2}{|l|}{$\mathrm{N} 1 \mathrm{~s}$} \\
\hline & & $\begin{array}{l}\text { Graphitic / } \\
\text { aliphatic }\end{array}$ & $-\mathrm{C}-\mathrm{O}-$ & $\mathrm{C}=\mathrm{O}$ & $-\mathrm{C}-\mathrm{O}-\mathrm{O}-$ & Nitrates $^{a}$ & Organic $^{\mathrm{b}}$ \\
\hline $\mathrm{Cu} / \mathrm{C}-\mathrm{C}$ & 100 & 80.7 & 11.7 & 4.5 & 3.1 & 94.1 & 5.9 \\
\hline $\mathrm{Cu} / \mathrm{C}-\mathrm{c}$ post & 76 & 32.8 & 40.3 & 16.9 & 10.0 & 31.6 & 68.4 \\
\hline $\mathrm{Cu} / \mathrm{C}-\mathrm{m}$ & 100 & 72.1 & 12.0 & 11.6 & 4.3 & 92.9 & 7.1 \\
\hline $\mathrm{Cu} / \mathrm{C}-\mathrm{m}$ post & 90 & 30.0 & 32.8 & 24.8 & 12.4 & 22.3 & 77.7 \\
\hline
\end{tabular}

a $\mathrm{N}$ species at $406-407 \mathrm{eV}$.

b $\mathrm{N}$ species at $399-400 \mathrm{eV}$.

Table 5

Elemental surface composition according to analysis by XPS.

\begin{tabular}{llrll}
\hline Sample & $\% \mathrm{C}$ & $\% \mathrm{Cu}$ & $\% \mathrm{O}$ & $\% \mathrm{~N}$ \\
\hline $\mathrm{Cu} / \mathrm{C}-\mathrm{c}$ & 20.4 & 18.9 & 52.4 & 8.3 \\
$\mathrm{Cu} / \mathrm{C}-\mathrm{c}$ post & 52.8 & 7.1 & 36.9 & 3.3 \\
$\mathrm{Cu} / \mathrm{C}-\mathrm{m}$ & 21.1 & 16.9 & 53.7 & 8.2 \\
$\mathrm{Cu} / \mathrm{C}-\mathrm{m}$ post & 66.3 & 3.2 & 23.8 & 6.7 \\
\hline
\end{tabular}

addition, the decrease observed in the values of the ID/IG ratio for the post samples suggests that pore covering effects take place on both monoliths. This latter result is also in good agreement with those observed by XPS. 

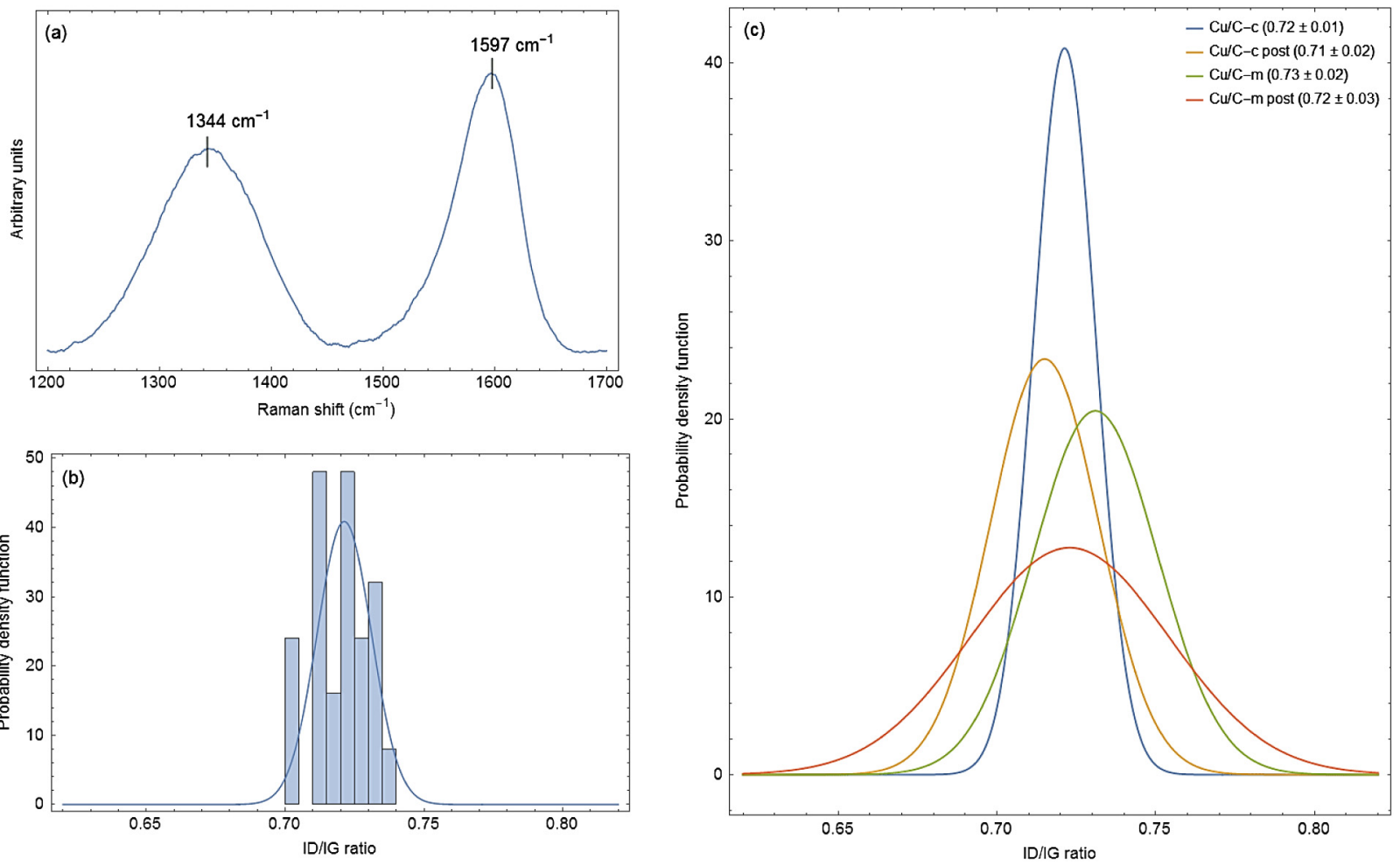

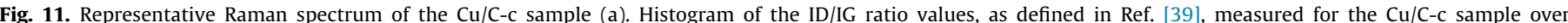

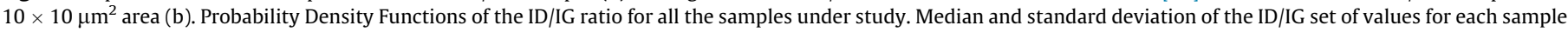
are indicated (c).

\section{Conclusions}

For the first time to our knowledge, carbon integral honeycomb monoliths have been used as support of copper catalysts in allylic oxidation reactions. In particular catalysts with good to excellent performance and high stability in the Kharasch-Sosnovsky allylic oxidation of cyclohexene have been prepared. Unlike homogeneous catalysis, the use of a solid catalyst avoids complex work up procedures, simplifies the isolation of the products, and allows the recycling of the catalyst. Furthermore, being unitary structures, honeycomb monoliths offer the additional advantage of an easier handling.

The study performed has demonstrated that the catalytic behavior can be very sensitive to some preparation variables such as the way of drying the carbon monoliths after being impregnated with the copper precursor. Moreover, a wide set of basic characterization techniques such as compositional and textural analysis, X-ray Diffraction measurements, study by SEM-EDS and TPR experiments have been employed to understand the origin of the better activity of conventionally dried samples in comparison with others assisted by microwaves.

The investigation carried out has demonstrated the great complexity of these supported catalysts, and the need of powerful tools to unveil important mechanistic aspects that may control the catalytic activity. In this sense, the application of XPS analysis to study the surface of the catalysts both at the beginning and after the reaction has been especially revealing. Thanks to this strategy it has been possible to distinguish subtle differences in the environment of $\mathrm{Cu}$ (II) cations over the surface which can be a key parameter. In particular copper seems to be surrounded by $\mathrm{O}^{2-}$ anions in the samples conventionally dried, and by $\mathrm{OH}^{-}$groups in those dried using microwaves. Also deposits of the reaction product have been identified as most likely cause of deactivation. Finally, the use of Raman Spectroscopy has allowed obtaining more details about the nature of the carbon present in the monoliths and its modification as consequence of the carbonaceous deposits formed during the reaction.

\section{Acknowledgements}

The authors thank the Ministry of Economy and Competitiveness of Spain (Projects CSD2009-00013, MINECO/FEDER MAT2013-40823-R, and AGL2013-42238-R) and the Junta de Andalucía (FQM-110 and FQM-169 groups) for their financial support. A.L. García-Cabeza and R. Marín-Barrios are grateful to the Spanish Ministry of Education, Culture and Sport for a fellowship. We also acknowledge the SC-ICYT of Cadiz University (UCA) for using its XRD, AS, NMR, MS and electron microscopy division facilities.

\section{References}

[1] A.B. Styles, Catalyst Supports and Supported Catalysts, Butterworths, Stoneham, MA, USA, 1987.

[2] J.M. Gatica, J.M. Rodríguez-Izquierdo, D. Sánchez, C. Ania, J.B. Parra, H. Vidal, Extension of preparation methods employed with ceramic materials to carbon honeycomb monoliths, Carbon 42 (2004) 3251-3254.

[3] J.M. Gatica, J.M. Rodríguez-Izquierdo, D. Sánchez, T. Chafik, S. Harti, H. Zaitan, H. Vidal, Originally prepared carbon-based honeycomb monoliths with potential application as VOCs adsorbents, C. R. Chim. 9 (2006) 1215-1220.

[4] J.M. Gatica, S. Harti, H. Vidal, Carbon honeycomb filters for o-xylene removal in gaseous phase, ACI 3 (1) (2012) 33-43.

[5] J.M. Gatica, S. Harti, H. Vidal, Changing the adsorption capacity of coal-based honeycomb monoliths for pollutant removal from liquid streams by controlling their porosity, Appl. Surf. Sci. 256 (2010) 7111-7117.

[6] M. Ouzzine, G.A. Cifredo, J.M. Gatica, S. Harti, T. Chafik, H. Vidal, Original carbon-based honeycomb monoliths as support of $\mathrm{Cu}$ or Mn catalysts for lowtemperature SCR of NO: effects of preparation variables, Appl. Catal. A 342 (2008) 150-158. 
[7] J.M. Gatica, D.M. Gómez, S. Harti, H. Vidal, Monolithic honeycomb design applied to carbon materials for catalytic methane decomposition, Appl. Catal. A 458 (2013) 21-27

[8] J.M. Gatica, G.A. Cifredo, G. Blanco, S. Trasobares, H. Vidal, Unveiling the source of activity of carbon integral honeycomb monoliths in the catalytic methane decomposition reaction, Catal. Today 249 (2015) 86-93.

[9] J.M. Gatica, H. Vidal, Use of coal to manufacture carbon integral honeycomb monoliths with environmental applications, in: J.A. Daniels (Ed.), Advances in Environmental Research, vol. 35, Nova Science Publishers Inc., New York, 2014, pp. 79-104.

[10] A. Levina, J. Muzart, Enantioselective allylic oxidation in the presence of the $\mathrm{Cu}$ (I)/Cu(II)-proline catalytic system, Tetrahedron: Asymmetry 6 (1) (1995) 147156.

[11] J. Eames, M. Watkinson, Catalytic Allylic Oxidation of alkenes using an asymmetric Kharasch-Sosnovsky reaction, Angew. Chem. Int. Ed. 40 (19) (2001) 3567-3571.

[12] M.B. Andrus, J.C. Lashley, Copper catalyzed allylic oxidation with peresters, Tetrahedron 58 (2002) 845-866.

[13] A.L. García-Cabeza, R. Marín-Barrios, F.J. Moreno-Dorado, M.J. Ortega, G.M. Massanet, F.M. Guerra, Allylic oxidation of alkenes catalyzed by a copperaluminum mixed oxide, Org. Lett. 16 (2014) 1598-1601.

[14] P. Cancino, V. Paredes-García, P. Aguirre, E. Spodine, A reusable Cu ${ }^{\mathrm{II}}$ based metal-organic framework as a catalyst for the oxidation of olefins, Catal. Sci. Technol. 4 (8) (2014) 2599-2607.

[15] D. Saha, T. Maity, R. Sen, Heterogeneous catalytic epoxidation of olefin over a hydrothermally synthesized 3D phosphate bridged copper(II) framework, J. Coord. Chem. 66 (14) (2013) 2444-2454

[16] A.L. Cánepa, C.M. Chanquía, G.A. Eimer, S.G. Casuscelli, Oxidation of olefins employing mesoporous molecular sieves modified with copper, Appl. Catal. A 462-463 (2013) 8-14.

[17] A.L. García-Cabeza, R. Marín-Barrios, R. Azarken, F.J. Moreno-Dorado, M.J. Ortega, H. Vidal, J.M. Gatica, G.M. Massanet, F.M. Guerra, DoE (Design of Experiments) assisted allylic hydroxylation of enones catalysed by a copperaluminium mixed oxide, Eur. J. Org. Chem. 36 (2013) 8307-8314.

[18] D.P. Debecker, V. Hulea, P.H. Mutin, Mesoporous mixed oxide catalysts via non-hydrolytic sol-gel: a review, Appl. Catal. A 451 (2013) 192-206.

[19] J. Carpentier, J.-F. Lamonier, S. Siffert, H. Laversin, A. Aboukaïs, Preparation and characterization of $\mathrm{Co}-\mathrm{Fe}-\mathrm{Cu}$ mixed oxides via hydrotalcite-like precursors for toluene catalytic oxidation, Stud. Surf. Sci. Catal. 142 (2002) 1197-1204.

[20] J.M. Rodríguez-Izquierdo, H. Vidal, J.M. Gatica, D. Sánchez, A.M. Cordón, Soportes monolíticos de base carbonosa y un procedimiento para su preparación, ES Patent 2221782 B1, University of Cádiz, Spain, 2005.

[21] E. Gippini, Pastas Cerámicas, Sociedad Española de Cerámica, Madrid, Spain, 1979.

[22] G. Cifredo, J.M. Gatica, S. Harti, H. Vidal, Easy route to activate clay honeycomb monoliths for environmental applications, Appl. Clay Sci. 47 (2010) 392-399.

[23] J.J. Rodríguez-Carvajal, Recent advances in magnetic structure determination by neutron powder diffraction, Physica B 192 (1993) 55-69.
[24] T. Vergunst, F. Kapteijn, J.A. Moulijn, Monolithic catalysts - non-uniform active phase distribution by impregnation, Appl. Catal. A 213 (2001) 179-187.

[25] W.H. Qi, M.P. Wang, Size and shape dependent lattice parameters of metallic nanoparticles, J. Nanopart. Res. 7 (1) (2005) 51-57.

[26] G. Fierro, M. Lojacono, M. Inversi, P. Porta, R. Lavecchia, F. Cioci, A study of anomalous Temperature-Programmed Reduction profiles of $\mathrm{Cu}_{2} \mathrm{O}, \mathrm{CuO}$, and CuO-ZnO catalysts, J. Catal. 148 (2) (1994) 709-721.

[27] M.S. Kharasch, G. Sosnovsky, The reactions of t-butyl perbenzoate and olefins a stereospecific reaction, J. Am. Chem. Soc. 80 (1958) 756.

[28] M.S. Kharasch, G. Sosnovsky, N.C. Yang, Reactions of t-Butyl peresters. I. The reaction of peresters with olefins, J. Am. Chem. Soc. 81 (1959) 5819-5824.

[29] M.C. Biesinger, L.W.M. Lau, A.R. Gerson, R.St.C. Smart, Resolving surface chemical states in XPS analysis of first row transition metals, oxides and hydroxides: Sc, Ti, V, Cu and Zn, Appl. Surf. Sci. 257 (2010) 887-898.

[30] M.C. Biesinger, B.R. Hart, R. Polack, B.A. Kobe, R.St.C. Smart, Analysis of minera surface chemistry in flotation separation using imaging XPS, Miner. Eng. 20 (2) (2007) 152-162.

[31] C.D. Wagner, A.V. Naumkin, A. Kraut-Vass, J.W. Allision, C.J. Powell, J.R.Jr Rumble, NIST Standard Reference Database 20, Version 3.4 (web version) (http://srdata.nist.gov/xps/), 2003.

[32] M.T. Martınez, M.A. Callejas, A.M. Benito, M. Cochet, T. Seeger, A. Anson, J Schreiber, C. Gordon, C. Marhic, O. Chauvet, J.L.G. Fierro, W.K. Maser, Sensitivity of single wall carbon nanotubes to oxidative processing: structural modification, intercalation and functionalization, Carbon 41 (2003) 2247-2256.

33] T. T Okpalugo, P. Papakonstantinou, H. Murphy, J McLaughlin, N.M.D. Brown, High resolution XPS characterization of chemical functionalised MWCNTs and SWCNTs, Carbon 43 (2005) 153-161.

[34] J.A. Mayoral, S. Rodríguez-Rodríguez, L. Salvatella, Theoretical insights into enantioselective catalysis: the mechanism of the Kharasch-Sosnovsky reaction, Chem. A Eur. J. 14 (30) (2008) 9274-9285.

[35] N. Komiya, T. Naota, Y. Oda, S. Murahashi, Aerobic oxidation of alkanes and alkenes in the presence of aldehydes catalyzed by copper salts and coppercrown ether, J. Mol. Catal. A 117 (1-3) (1997) 21-37.

[36] C. Dossi, A. Fusi, G. Moretti, S. Recchia, R. Psaro, On the role of carbonaceous material in the reduction of $\mathrm{Cu}^{2+}$ to $\mathrm{Cu}^{+}$in $\mathrm{Cu}-\mathrm{ZSM}-5$ catalysts, Appl. Catal. A $188(1-2)(1999) 107-119$.

[37] S. Carloni, B. Frullanti, R. Maggi, A. Mazzacani, F. Bigi, G. Sartori, Allylic oxidation of olefins in the presence of Cu-Na-HSZ-320 zeolite as reusable solid catalyst, Tetrahedron Lett. 41 (2000) 8947-8950.

[38] H.E.B. Lempers, R.A. Sheldon, The stability of chromium in CrAPO-5, CrAPO-11, and CrS-1 during liquid phase oxidations, J. Catal. 175 (1998) 62-69.

[39] M.S. Dresselhaus, A. Jorio, A.G. Souza Filho, R. Saito, Defect characterization in graphene and carbon nanotubes using Raman spectroscopy, Philos. Trans. R. Soc. A 368 (2010) 5355-5377.

[40] S. Reich, C. Thomsen, Raman spectroscopy of graphite, Philos. Trans. R. Soc Lond. A 365 (2004) 2271-2288.

[41] J.-S. Roh, Structural study of the activated carbon fiber using laser Raman spectroscopy, Carbon Lett. 9 (2008) 127-130. 